\title{
Vida criminal en las colonias agrícolas de la Provincia de Antio- quia a finales del siglo XVIII
}

\section{Criminal life in the agricultural colonies in the Province of Antioquia at the end of the 18th century}

\author{
Cristian Camilo Betancur Arboleda \\ Universidad de Antioquia \\ cristianc.betancur@udea.edu.co
}

Fecha de recepción: 24 de julio de 2018

Fecha de aprobación: 7 de octubre de 2018

\begin{abstract}
Resumen
El presente artículo, examina la vida criminal dentro de algunas de las colonias agrícolas establecidas en las postrimerías del siglo XVIII en la Provincia de Antioquia, las cuales se cimentaron bajo los designios ilustrados que provocaron las Reformas Borbónicas. Además, el texto analiza los fenómenos que causaron la necesidad de la fundación de dichas colonias, cuya razón principal era la de proveer de alimentos a las zonas mineras. Por otra parte, la fundación de dichas colonias, a la vez buscaba agrupar a la población dispersa, que para la época eran denominados vagos y ociosos. Estas pretendían no solamente fomentar la agricultura y servir a la minería, sino también establecer "vida en policía", es decir, una comunidad de vasallos obedientes de las ordenes de la Corona y de la ley divina. Sin embargo, esa pretendida vida controlada por un Estado lejano se podía quebrantar.
\end{abstract}

Palabras Clave: Colonias agrícolas, Criminalidad, Reformas Borbónicas, Ociosidad.

\begin{abstract}
The current article analyses the criminal life within some farming colonies established in the late 18th century in the province of Antioquia. These colonies were founded under the command of that period that turns out in the Borbonic monarchy reforms. In addition, the article analyses the causes that led to the necessity of creation of these colonies. The main reason was to create a farming land close to the mine land in order to supply food. These farming colonies aimed to get workforce from the community who did not have a duty or any other activity to do. They were called the "lazy" or "idle" by the time. The rulers of these colonies pretended not only to have farming and mining lands but also to control the colonies with loyal servants under the order of the crown and under god. Nonetheless, this kind of ruling by a further power could break down in any moment.
\end{abstract}

Key Words: Farming colonies, Criminality, Borbonic Monarchy, Idleness. 


\section{Consideraciones iniciales}

Estudiar la vida cotidiana en el periodo colonial es una empresa que resulta compleja debido a que no existen fuentes o fondos documentales que de manera exclusiva aludan a la "vida cotidiana" o a las "costumbres de la gente"; sin embargo, esto no quiere decir que no se puedan documentar aspectos tales como: las formas de vestir, de comer, de celebrar, las conflictividades o los crimines. Para dar cuenta de los detalles anteriores, el historiador debe conocer y manejar con propiedad su materia prima, es decir, las fuentes. Así sabrá cuáles son los fondos más ricos para el estudio de la vida cotidiana. Asimismo, la indagación de la población siempre debe ir enmarcada dentro de un contexto histórico, dado que este es el que determina los tipos de relaciones, comportamientos y actitudes de la población en general. Para el presente ejercicio de investigación, se tomará como periodo de análisis, las postrimerías del siglo XVIII, haciendo énfasis en el estudio de la vida criminal dentro de las colonias agrícolas adelantadas por el visitador Juan Antonio Mon y Velarde a partir de la década de 1780. Debe advertirse que esta breve investigación no se centrará en una determinada colonia; lo que se pretende es mirarlas como un conjunto y, dado el caso, tomar algunas como marco explicativo'.

Durante la indagación de bibliografía no se encontró ningún libro que abordara la vida cotidiana en las colonias agrícolas; como sí investigaciones que sirvieron a la hora de crear un contexto general y específico antes, durante y después de su establecimiento. Así, uno de los trabajos que atravesará transversalmente la investigación es el Trabajo de Grado del historiador de Mauricio Arango Puerta, que lleva por título Poblamiento agrícola en la Provincia de Antioquia 1754-1812. En él, aborda los patrones de poblamiento a finales del siglo XVIII y principios del XIX, haciendo hincapié en el poblamiento agrícola. Aunque, como se ha mencionado, no da muchos atisbos sobre la cotidianidad de las personas en las colonias, fue de obligatoria consulta.

Otro trabajo que fue útil para rastrear a los colonos pobladores de las colonias agrícolas, es el de la historiadora Beatriz Patiño Millán, Riqueza, pobreza y diferenciación social en la Provincia de Antioquia durante el siglo XVIII. La profesora Patiño realizó un riguroso trabajo sobre el acceso y ocupación de las tierras por parte de los diferentes grupos étnicos en las grandes ciudades de la Provincia de Antioquia. De la misma autora, otro libro de gran importancia para la presente investigación es Criminalidad, Ley Penal y Estructura social en la Provincia de Antioquia. 1750-1820. Dicha investigación será la base que nos permitirá entender cómo funcionaban los juicios criminales, teniendo en cuenta muchas de las fuentes primarias encontradas

1 Para no repetir constantemente a lo largo del trabajo el nombre de las colonias, las mencionaré aquí y solo se aludirá individualmente a cada una cuando sean necesario, así que cuando se hable de colonias agrícolas se debe pensar principalmente en las siguientes: San Antonio del Infante, San Luis de Góngora, San Carlos del Priego, San Fernando de Borbón y Carolina del Príncipe. 
para realizar la investigación sobre los crímenes en las colonias agrícolas son juicios criminales.

Existe una investigación que aborda de manera puntual las colonias agrícolas. Este es el Trabajo de Grado del historiador Rodrigo Campuzano Cuartas, que lleva por título "Fundaciones de Yarumal, Sonsón, San Carlos y Amagá". Esta extensa investigación está llena de datos y análisis de las fundaciones de aquellos centros y fue de gran ayuda para entender ciertos procesos en el establecimiento de las colonias. Los anteriores trabajos son los más representativos, lo que no significa que existan otros, que también serán utilizados en la investigación.

En cuanto a las fuentes primarias que se utilizarán, se debe decir que, luego de una búsqueda minuciosa en los cuatro tomos de índices de la sección colonia del Archivo Histórico de Antioquia y en los tres tomos que existen sobre juicios criminales en el mismo archivo, se identificaron diferentes fondos que contienen información de las colonias agrícolas. De esta forma, los fondos encontrados son muy variados: Reales Ordenes, Órdenes Superiores, Fundaciones, Policía, Empleos, Tierras, Minas Visitas y Erección de Curatos. De estos, los más ricos en información relativos a nuestro tema son, el fondo Erección de Curatos y Fundaciones, puesto que allí se pueden observar los orígenes de las colonias agrícolas. Asimismo, haciendo el rastreo de juicios criminales, se hallaron al menos veinte casos en los cuales se alude a los ocurridos en las colonias agrícolas.

Vale la pena señalar que a lo largo del siglo XVIII la Corona trató de implementar una serie de reformas en la administración y control de sus dominios. Varias fueron las justificaciones de esas reformas, que ya han producido una historiografía importante ${ }^{2}$.

Una faceta destacada del Reformismo borbónico, tuvo que ver con el control social; la "vida en policía" se convirtió en un objetivo de las autoridades. Mantener a la población controlada, ordenada, estable y "al son de campana", justificaron las acciones de personajes como José Fernando de Mier y Guerra, en la gobernación de Santa Marta, Antonio de la Torre y Miranda y Josep Palacios de la Vega, en la gobernación de Cartagena, y Juan Antonio Mon y Velarde en Antioquia, para citar solo unos ejemplos del Nuevo Reino de Granada. Congregar a población dispersa, establecer sitios, instaurar un orden y definir autoridades, fue algo común en esas provincias y en otros lugares de la América española.

2 Enrique Florescano, 1750-1808: la época de las reformas borbónicas y del crecimiento económico (México: Departamento de Investigaciones Históricas, 1974); Luis Navarro García, Las Reformas Borbónicas en América: el Plan de Intendencia y sus aplicaciones (Sevilla: Universidad de Sevilla, 1995); Clara García Ayluardo, Las Reformas Borbónicas, 1750-1808 (México: Fondo de Cultura Económica, 2010) y, Marta Clemencia Herrera Ángel, Ordenar para controlar: ordenamiento espacial y control político en las Llanuras del Caribe en los Andes Centrales neogranadinos siglo XVIII (Bogotá: Instituto Colombiano de Antropología e Historia, 2002). 
¿Qué había tras esos poblamientos? Además del control social, interesaba fomentar la agricultura. Una muestra de la llegada de la fisiocracia, corriente del pensamiento económico dieciochesco, que proponía que la agricultura debía ser fomentada por el Estado, pues era una actividad económica que garantizaba el acceso a la alimentación, y al tiempo generaba apego a la tierra, con lo que podrían desarrollarse los intereses del control poblacional. ${ }^{3}$

Así, en la década de 1780, se fomentaron las colonias agrícolas de San Fernando de Borbón (hoy Amagá), al sur de la provincia; San Carlos de Priego, al oriente; y en el Valle de los Osos, la rica zona minera del norte, las de San Luis de Góngora (hoy Yarumal), San Antonio de Infante, hoy Don Matías, y Carolina del Príncipe.

Las colonias agrícolas, fueron el resultado de una colonización dirigida, promovida por el visitador Mon y Velarde, un funcionario español fiel representante de las ideas ilustradas emanadas por la dinastía de los borbones. Juan Antonio Mon estuvo en la provincia de Antioquia entre 1785 y 1788. Emprendió varios proyectos en la gobernación, todo con el fin de "ordenar para controlar". Hizo parte de una generación de funcionarios, que manifestaron la llegada del reformismo borbónico a la pobre y apartada gobernación antioqueña ${ }^{4}$. Ahora bien, el establecimiento de dichas colonias tuvo una historia de larga data y estuvo directamente vinculada con la minería. Durante el siglo XVII, una vez el primer ciclo del oro declinó, las ciudades en las que se desarrolló el primer modelo de poblamiento basado en el metal precioso (Cáceres, Zaragoza y Guamacó) también decayeron, aunque no desaparecieron ${ }^{5}$. A finales del siglo XVII se desarrolló el segundo ciclo minero, que se trasladó a la zona montañosa del Valle de los Osos.

Una de las razones por las cuales decayeron los centros mineros hacía 1630 fue la falta de territorios agrícolas dedicados a abastecer a los reales de minas. Es así que, para el siglo XVIII, un motivo para la fundación de las colonias agrícolas era el de abastecer a los centros mineros ubicados en el altiplano de los Osos y otros lugares de la Provincia, como señala Mauricio Arango: "En términos del pensamiento de los funcionarios borbones, para que en Antioquia la producción del oro volviera a su antiguo esplendor debía de solucionar primero los inconvenientes del abastecimiento" ${ }^{\text {. }}$

3 Si el lector desea profundizar acerca del concepto de "fisiocracia" ver, Eric Roll, Historia de las doctrinas económicas (México: Fondo de Cultura Económica, 1994).

$4 \quad$ Así la definía Roberto Luis Jaramillo, quien aseguró que la provincia de Antioquia en el siglo XVIII "no se distinguía por su extensión, ni por sus suelos agrícolas, era una de las más desfavorecidas y atrasadas del entonces Nuevo Reino de Granada, donde gobernadores y alcaldes ejercían su débil gobierno sobre ciudades y villas desarticuladas con límites imprecisos." Roberto Luis Jaramillo, "Colonizaciones en Antioquia," en: Geografia de Antioquia, ed. Michel Hermelin (Medellín: Fondo Editorial Universidad Eafit, 2007), 63.

5 Germán Colmenares, La formación de la economía colonial (1500-1740), Biblioteca virtual Banco de la República, http://www.banrepcultural.org/blaavirtual/economia/histecon/histecon2a.htm (Consultado: 11 de octubre de 2017).

6 Mauricio Arango Puerta, "Poblamiento agrícola en la provincia de Antioquia, 1754-1812" (Monografía de pregrado, Universidad Nacional de Colombia, sede Medellín, 2010), 43. 
Además, estaba también presente el ideal de control social. Al interior de las colonias agrícolas se desarrolló todo un proceso de sociabilización e integración de individuos de diversa índole que, buscando nuevas oportunidades que les permitieran poseer una parcela de tierra, se vieron tentados u obligados a mudarse a la periferia de las grandes jurisdicciones de Antioquia para habitar las colonias. Es factible pensar, entonces, que una nueva población integrada por una capa tan diversa de colonos fuera el caldo de cultivo para que se presentaran conflictos, ya fuera entre los mismos colonos o entre vecinos que quisieran sacar ventaja de las concesiones de tierra. Esta parte conflictiva dentro de las colonias agrícolas es la que se pretende estudiar a través de la mejor fuente para ello, los juicios criminales. Así pues, las preguntas que se tratarán de resolver en la investigación serán: ¿Por qué se establecieron las colonias agrícolas en la Provincia de Antioquia a finales del siglo XVIII?, ¿Cómo funcionaba el proceso de erección de una colonia agrícola?, ¿Realmente las colonias agrícolas fueron efectivas para agrupar a la población dispersa? Y, por último ¿Efectivamente existió una vida criminal dentro de las colonias agrícolas?

\section{Colonias agrícolas}

Dentro de este apartado, se describirá el origen, la forma cómo debía poblarse, quienes la integraban, la función de los jueces pobladores y otros detalles de las colonias agrícolas establecidas en la Provincia de Antioquia a finales del siglo XVIII.

Para comenzar, quisiera reiterar que se debe tener presente, como marco histórico, las Reformas Borbónicas, ejecutadas en el siglo XVIII en toda la América hispánica. Estas tenían como objetivo generar un mejor manejo administrativo y económico de las colonias para así hacerlas más rentables para la metrópoli. Las medidas buscaron ponerle freno a la ausencia de un control efectivo y total en los dominios de la Corona, propia de tiempos de los Austrias. De esta manera, la atención de los reformistas recayó en la lucha contra el contrabando, la extracción de metales preciosos, la productividad económica, la defensa del territorio, la promoción de mecanismos para el cobro y regulación de impuestos, la creación de nuevos cargos administrativos, entre otros.

Aunque las reformas iniciaron de la mano de Felipe V de Borbón a principios del siglo XVIII, estas fueron más agresivas en tiempos de Carlos III, entre 1759-1788. El Nuevo Reino de Granada no fue ajeno a las reformas, el Regente Visitador Juan Francisco Gutiérrez de Piñeres en el año 1778 fue el encargado de promover, difundir y hacer cumplir las reformas en el territorio. Haciendo uso de sus facultades implementó modificaciones de tipo fiscal que más tarde desencadenaría en la Rebelión de los Comuneros en 1781, que se extendería por otras partes del territorio, incluida la Provincia de Antioquia. 
Cabe anotar que no todas las alteraciones fueron de tipo fiscal, también dichas reformas apuntaron a la moralidad y al comportamiento del pueblo. Así pues, armados por la razón, la dinastía borbónica decidió conocer, en una primera instancia, el estado actual de sus súbditos de ultramar, para identificar y reformar sus "vicios" y "males" con el fin de llevar a cabo una serie de soluciones que suponía una mejora en los comportamientos que se consideraban reprochables. Para el caso de Antioquia, dicha labor estuvo a cargo principalmente de los gobernadores, quienes para el siglo XVIII, ya no eran unos simples administradores "sino que actores voluntariosos, pragmáticos, celosos del orden -a través de la promulgación de bandos de policía y de "buen gobierno"-, amantes de la autoridad"7

En sus recorridos por la provincia de Antioquia, los funcionarios españoles lo que encontraron fue la dispersión en que se hallaban las personas en la provincia, - $\mathrm{a}$ pesar de esta poseer grandes riquezas auríferas y agrícolas- así lo certificó Mon y Velarde en su Sucinta Relación al hablar de los distintos sitios y ciudades de la provincia, por ejemplo, cuando hace mención de Envigado dice, "Santa Gertrudis del Envigado, que se halla como a trece leguas de su cabecera, es una población numerosa; y aunque dispersa como las demás, se hallan familias colocadas en el mismo sitio. ${ }^{8}$ " Pero, entonces, ¿Si el problema no era la fertilidad de los terrenos, por qué gran parte del territorio se encontraba sin ser ocupado ni trabajado? La profesora Beatriz Patiño, en su trabajo Riqueza, pobreza y diferenciación social en la provincia de Antioquia del siglo XVIII, problematiza dicha situación e identifica tres causas que llevaron a que los pobladores sin tierra se vieran obligados a establecerse como agregados, arrendatarios o mercenarios en tierras ajenas: La monopolización de la tierra por parte de una minoría blanca; el aumento acelerado de la población mestiza y mulata, y la manumisión de esclavos. ${ }^{9}$

Entonces, existían grandes propiedades de tierras en pocas manos y un número significativo de pobladores sin ella, lo que los llevó a someterse a las condiciones que impusieran los terratenientes. Pero lo anterior no fue la única consecuencia de lo identificado por la profesora Patiño; el hecho de no encontrar su lugar en una sociedad estratificada, llevó a que muchos de ellos leyeran su realidad de manera distinta y decidieran irse a otros parajes a buscar soluciones a sus problemas de tierra o simplemente se convirtieran en personas itinerantes que iban de un lado al otro, es decir, bajo la jerga de la época eran "vagos", "mal entretenidos" y "ociosos".

Como se dijo al inicio del trabajo, el establecimiento de las colonias agrícolas

$7 \quad$ Jaime Valenzuela Márquez, Fiesta, rito y política. Del Chile borbónico al Republicano (Santiago: Dirección de Bibliotecas, Archivos y Museos, 2014) 66.

8 Emilio Robledo, Sucinta Relación. Bosquejo biográfico del señor oidor Juan Antonio Mon y Velarde Visitador de Antioquia, 1785-1788 (Bogotá: Publicaciones del Banco de la República, 1954), 11.

9 Beatriz Amalia Patiño Millán, Riqueza, pobreza y diferenciación social en la Provincia de Antioquia del siglo XVIII (Medellín: Facultad de Ciencias Sociales y Humanas, Universidad de Antioquia, 1985), 193. 
fue un proceso, en términos de Braudel, de larga duración, por lo menos así lo entiende Arango al decir que:

El análisis de la colonización en Antioquia durante el siglo XVIII puede observarse a partir de la apertura de fronteras económicas. En este caso, pueden distinguirse dos procesos a grandes rasgos. A finales del siglo XVII las fronteras internas de la provincia se movieron desde el primer núcleo de poblamiento — que se ubicaba sobre las ciudades de Cáceres, Zaragoza, Guamacó- hacia las partes montañosas de la cordillera central, lo que puede interpretarse como un movimiento de la periferia hacía el centro con el cual se afianzó el poder político y económico en los valles de los Osos, Aburrá y Rionegro. De manera inversa, encontramos que el movimiento de las fronteras a finales del siglo XVIII, en parte, producto del poblamiento dirigido sobre las denominadas cuatro colonias de Mon y Velarde, desplazándose los colonos del centro a la periferia. ${ }^{10}$

Se observa pues, cómo fue el movimiento de las fronteras económicas en la Provincia de Antioquia desde finales del siglo XVII hasta concluir el XVIII. Ahora bien, a modo de explicación general de dicho proceso se puede decir que una de las razones por las cuales el primer núcleo de poblamiento basado en el auge minero decayó, fue el poco abastecimiento agrícola que tenían los grandes centros auríferos para mantener las numerosas cuadrillas de esclavos, lo que llevó a que se mudaran a los ricos valles de Rionegro, Aburrá y los Osos, que poseían tierras más aptas que permitieran sostener las labores mineras y la provisión de las ciudades; esto a través del establecimiento de nuevas poblaciones que cumplieran con el fin descrito.

Según se ha visto, se pueden identificar dos causas - problemas- que propiciaron el adelanto de las colonias agrícolas en la Provincia de Antioquía a finales del siglo XVIII: por un lado, se identificaron los problemas plantados por Patiño y sus consecuencias directas sobre la población sin tierra que se vio obligada a trabajar en las grandes propiedades; migrar buscando nuevas oportunidades; o llevar una vida "ociosa". Por otro lado, el establecimiento de las colonias, tuvo que ver con la resolución de un problema histórico: el abastecimiento de los centros mineros y las ciudades. A continuación, se analizará cómo las autoridades ejecutaron la fundación de los centros y buscaron las soluciones a los problemas mencionados.

\section{2. "Sin Dios, sin ley y sin Rey"}

La población dispersa en el Nuevo Reino de Granada fue un fenómeno que existió incluso antes de la ocupación española, el cual, una vez establecidos aquellos, prevaleció, provocando que el poder real tomara cartas en el asunto. Así lo han mostrado 
las investigaciones que han abordado el tema del poblamiento durante el Periodo Colonial. De esta forma sucedió, por ejemplo, en la Provincia de Cartagena, donde durante los siglos XVI y XVII, se fue consolidando un patrón de poblamiento alejado del control político y eclesiástico. En la misma provincia casi dos siglos después, en pleno auge de las Reformas Borbónicas, aparece un personaje clave para solucionar dicho problema: Antonio de la Torre y Miranda; quien tenía como una de sus tareas, controlar a la población dispersa que vivía al margen de las dos repúblicas. De esta manera, de la Torre realiza un reordenamiento territorial, el cual consistía en congregar a las personas dispersas de toda la provincia en parroquias de vecinos libres por medio del trabajo de la tierra. ${ }^{11}$ Así, la idea de congregar a poblaciones dispersas alrededor de colonias agrícolas no es única de la Provincia de Antioquia, más bien, es una idea generalizada en todo el Nuevo Reino de Granada, emanada por los nuevos ideales fisiócratas europeos.

Ahora bien, la Provincia de Antioquia no fue ajena a lo anterior y bajo el impulso del Visitador Mon y Velarde se establecieron varias colonias agrícolas en los últimos decenios del siglo XVIII para solucionar los grandes problemas de la población dispersa, la vagancia y la explotación minera y agrícola. Aunque fue aquel quien las llevo a feliz término, Pedro Rodríguez Zea sugirió en 1785 que se establecieran, primeramente, cuatro poblaciones en el Valle de los Osos, diciendo que: "para poder efectuar estas fundaciones opinaba que era necesario dar tierras gratuitas a todos los colonos que quisieran dedicarse a las labores agrícolas y mineras." - Tres años después-

(...) el visitador Juan Antonio Mon y Velarde ordenó la fundación de las colonias de San Luis de Góngora (hoy Yarumal), San Antonio del Infante (hoy Don Matías) Carolina del Príncipe y San Carlos de Priego, en un claro ejemplo de la política borbónica sobre poblamiento. ${ }^{12}$

En ese mismo sentido, debe entenderse que en las colonias agrícolas, el poblamiento dirigido o disperso en la provincia de Antioquia, no fue un fenómeno que solo se dio durante los últimos decenios del siglo XVIII, antes de establecerse formalmente un sitio, este casi siempre ya se encontraba poblado, por lo tanto como asegura Arango, no debe mirarse el poblamiento solo desde los postulados de Mon y Velarde y Francisco Silvestre ${ }^{13}$.

11 Para profundizar en la labor hecha por Antonio de la Torre y Miranda se puede consultar el trabajo de Jorge Conde Calderón que abarca los conflictos por el espacio y la reorganización del territorio de Cartagena. Jorge Conde Calderón, Espacio, Sociedad y Conflictos en la Provincia de Cartagena, 1740-1815 (Barranquilla: Fondo de Publicaciones de la Universidad del Atlántico, 1999).

12 Juan David Montoya, "Antioquia: población y territorio en las postrimerías del periodo colonial," Historia y Sociedad 14, (2008): 235.

13 Arango Puerta, Poblamiento agrícola, 79. 
Siguiendo las consideraciones anteriores, es necesario resaltar un hecho fundamental que tendría mucho que ver en el desenlace de las colonias, se trata de la Real Cédula de 1780, la cual proporcionó mayores posibilidades para que los pobladores sin tierra accedieran a esta, puesto que en aquella quedaba estipulado que:

En lo respectivo a las tierras baldías... pertenecen a mi Real Patrimonio y de consiguiente puede éste enajenarlas, he resuelto conforme por lo expuesto por el fiscal de esta Audiencia (...) que se concedan graciosamente a los sujetos que las quisiesen desmontar (...) sembrar y cultivar y mantenerlas siempre cultivada con pastos o con siembras según su naturaleza. ${ }^{14}$

De este modo, la Corona decidió conceder tierras a aquellos pobladores sin tierra en vez de venderlas. Esta Real Cédula se convirtió en el arma principal de Mon y Velarde para las fundaciones de las colonias, abriendo una ventana al acceso a la tierra de los pobladores pobres. No se debe tomar dicha decisión como un gesto altruista por parte de las autoridades, lo que en realidad pretendían era, entre otras cosas, agrupar a personas que se encontraban dispersas, para convertirlos en gentes útiles para la Corona y para Dios.

La vagancia en toda la Provincia de Antioquia fue un problema que iba en aumento durante los últimos años del siglo XVIII. Así lo afirma Beatriz Patiño, cuando analiza las sociedades del oriente antioqueño y el valle de Aburrá; sobre este último dice que en Medellín y Envigado existían cerca de 500 vagos que se dedicaban a robar y fomentar los vicios. ${ }^{15}$ La solución más efectiva que surgió para combatir estos comportamientos "dañinos", a la luz de la Real Cédula de 1780, fue la agrupación de aquellos "vagos, ociosos y malentretenidos ${ }^{16 "}$ en labores productivas.

Se observa, entonces, cómo entran en juego los discursos dieciochescos acerca de la utilidad de las personas, es decir, el hecho de valorar la población del Nuevo Reino como una riqueza incalculable, más que la tierra en sí misma, puesto que de nada vale un sinnúmero de tierras fértiles y aptas para la explotación, si no se tiene mano de obra para ponerlas a producir. Esto lo observo muy bien Mon y Velarde, quien pen-

14 Rodrigo Campuzano Cuartas, "Fundaciones de Yarumal, Sonsón, San Carlos y Amagá” (Monografía de pregrado, Universidad de Antioquia, 1986), 23.

15 Patiño Millán, Riqueza, pobreza, 277.

16 Juan Carlos Jurado, en su trabajo Vagos, pobres y mendigos define de manera interesante, qué era Para la Corona un vago, ocioso y un malentretenido. "(...) a los "vagos", en oposición a los "ociosos", se los caracterizaba por su movilidad geográfica, eran vagantes. (...) De ahí que, a los falsos pobres, con capacidad de trabajar, se les tratara definitivamente como vagos, que, junto con los ociosos, se calificarían como ladrones de la República (...) en cuanto a los denominados malentretenidos, esta categoría parecía designar una amplia serie de comportamientos prohibidos, y en particular a holgazanes dedicados a entretenimientos perjudiciales en juegos y tabernas, y una vida voluptuosa de abandono de las obligaciones familiares y laborales." Juan Carlos Jurado Jurado, Vagos, pobres y mendigos. Contribución a la historia social colombiana, 1750-1850 (Medellín: La Carreta Editores, 2004), 43. 
saba que el trabajo era la única forma de redimirse ante Dios y la patria, como queda claro en la siguiente cita:

Solo pudiera haberla facilitado la viva impresión que por todos términos les hice concebir, desde los más grandes hasta los más pequeños, que todos habíamos nacido para el trabajo, y que debía mirarse como delincuente en la sociedad humana al que era inútil a la patria y no empleaba sus fuerzas y talentos en procurar por sí mismo su subsistencia; pues lo demás era ser ingrato al soberano Autor de la naturaleza y público ladrón de la República, a quien defraudaba de sus servicios. ${ }^{17}$

En consecuencia, la Corona buscó, a través de sus funcionarios, atraer a la "población flotante", agruparla y establecerla alrededor de la tierra para que la trabajaran. Ahora, para terminar este breve apartado, es conveniente cerrar con la visión general que tenía Mon y Velarde de la sociedad Antioqueña de finales del siglo XVIII y la sorpresa que le causó que precisamente las gentes "faltas de costumbres" se juntaran en nuevas poblaciones.

Que una gente bizarra, pundonorosa y amante de su gloria atraída de la novedad y de la esperanza dejasen su domicilio, abandonándose en manos de la fortuna, nada tenía de nuevo ni de particular; pero que unos hombres sin costumbre, bien hallados y contentos con su pobreza y desdicha, adormecidos en el regazo de la ociosidad, criados en un país donde todo se ejecuta por imitación, y se desprecia cundo tiene visos de novedad, hayan querido hacer casas, arrasar montes, experimentar nuevos climas y vivir, en fin, como los más industriosos es empresa que aun después de realizada la miro como fabulosa. ${ }^{18}$

\section{Establecimiento de las colonias}

Ya se ha comentado y analizado, de manera general, las causas y las razones que llevaron a que se establecieran las colonias agrícolas en la Provincia hacía las postrimerías del siglo XVIII. A continuación, se dará cuenta, a través de fuentes de época, la forma y la estructuración que debían seguir las colonias una vez se autorizaban. Para no caer en una explicación esquemática solo tomaré como ejemplo algunas colonias para facilitar la explicación.

La documentación observada permite trazar una idea general sobre cómo se debían erigir los nuevos poblados, lo anterior, partiendo de las llamadas "instrucciones" que Mon y Velarde entregaba a los funcionarios encargados de fomentar el poblamiento; esta figura se conoció con el nombre de juez poblador que según Campuzano

17 Robledo, Bosquejo biográfico, 91-92

18 Robledo, Bosquejo biográfico, 91. 
era casi siempre era una persona reconocida y con una vida económica activa, ${ }^{19}$ lo que generó varios conflictos como se señalará más adelante. Así pues, durante la indagación de los fondos referentes a la fundación de nuevos sitios, se encontró con que todos guardaban una misma estructura, es decir, las instrucciones iban guiadas a promover una población organizada, establecer controles morales, fomentar la religión, informar de las personas que llegasen, construir iglesia, plaza, cárcel, entre otras. Para ejemplificar lo anterior, se traerán dos instrucciones de las tantas que concedió el visitador.

(...) se pueblen sus vastos dominios se reformen las costumbres, y se mantenga la Religión Católica con toda la firmeza, que corresponde: deberá ser el primer cargo y más preferente objeto de su atención celar la honra de Dios, impedir escándalos, y extirpar vicios, y procurar en todo que los nuevos habitantes vivan como verdaderos fieles en paz y concordia ayudándose mutuamente. ${ }^{20}$

La anterior es la primera instrucción que se les entregaba a los jueces pobladores; allí se puede evidenciar que primeramente lo que buscaban era mantener a la población "al son de campana" a través de una vida cristiana libre de excesos y entregada al trabajo. Pero para alcanzar esta primera instrucción era necesario establecer o crear los símbolos primarios de un establecimiento fijo: la iglesia, la plaza y la cárcel, es por ello que otra de las indicaciones más urgente que se les hacía a los jueces era:

(...) procederá a formar un plan del nuevo sitio señalando primeramente el terreno, para edificar; colocará la Plaza Mayor en el centro de este sitio, medirá ocho cuadras por cada costado de á cien varas, señalará terreno capaz y espacioso donde pueda hacerse Iglesia con suficiente extensión, y comodidad. ${ }^{21}$

El establecimiento de un orden espacial, puede decirse que es lo que le da legitimidad al acto de población puesto que, por un lado, con la construcción de la iglesia como lugar central, se crea ese pacto divino entre los colonos y Dios mientras que, por otro lado, la edificación de la cárcel, hace pensar que existen organismos de control encargados de administrar justicia y, por último, al construirse la plaza principal, esta se constituye como el lugar común donde todos los grupos étnicos tenían lugar. De esta manera, estos lugares sirvieron para mantener y reafirmar el orden jerárquico por parte de las autoridades, a la vez también fueron las zonas de convivencia para todas las personas, porque era allí donde se realizaban las fiestas, los mercados, los actos políticos y la aclamación a Dios.

19 Campuzano Cuartas, "Fundaciones, 37.

20 "Documentos sobre tramite de fundación de San Fernando de Borbón, hoy Amagá" (Medellín 16 de abril de 1790). AHA, Colonia, FM, t. 41, hoja 33, f. 1r.

21 "Documentos sobre tramite de fundación de San Fernando de Borbón, hoy Amagá" (Medellín 16 de abril de 1790). AHA, Colonia, FM, t. 41, hoja 33, f. 3v. 
Aunque son muchas más las instrucciones encontradas, la mayoría apuntan a lo anterior, el ordenamiento territorial y el control social de los nuevos colonos, esto al menos dentro de los discursos formales y lineales de los jueces pobladores. Otra de las obligaciones-entre las muchas que tenían los jueces pobladores - era la de enviar informes cada seis meses detallando el número de personas que allí se hallaban, los cultivos que se producían, el estado de la iglesia y demás averiguaciones importantes de las colonias agrícolas. Así lo hizo don José María del Toro, juez poblador de la Colonia de San Carlos del Priego en la jurisdicción de Marinilla, quien remitió un vasto informe al gobernador en 1789 , donde hacía una descripción muy optimista de la colonia diciendo que se encontraba muy adelantada y que no se conocían vicios, a manera de resumen anota el juez:

(...) hay edificadas cincuenta, y siete casas, su iglesia de treinta, y media vara de largo, y trece de ancho. (...) su cárcel de ocho varas de largo: La tierra es pingue para todo fruto de caña dulce, maíz, plátano de las tres especies, cacao; en el año hay dos cosechas de maíces, y de todo lo dicho tienen sus sembrados estos vecinos: igualmente es pingue para los ganados vacunos, de que puede pasar de cien reces las que hay en esta población; su temperamento es templado, más cálido que frio... Las minas son muchas para cuadrillas; (...) Por tanto Señor ruego a vuestra majestad. Haga todos sus esfuerzos con el excelentísimo Señor. a fin de que se nos conceda cura propio, que es lo que más nos desconsuela... como también el que se nos franqueen algunas herramientas y algún socorro para acabar de adornar nuestra Yglesia pues apenas hemos podido conseguir cuarenta y (no se alcanza a ver el otro número) castellanos y medio que hemos destinado para los vasos sagrados. ${ }^{22}$

Incluso al final del documento se incluye un padrón de las personas avecindadas en San Carlos del Priego, que, aunque no es especifico en cuanto a las calidades étnicas u ocupaciones de los colonos, por lo menos ayuda a hacerse la idea del número de personas que la habitaban, que según dice del Toro eran, para 1789, 50 familias que dan un total de 264 personas. ${ }^{23}$ Estas cifras deben mirarse con cuidado, dado que es posible que hayan quedado por fuera colonos o también que se hayan agregado más. Aunque se podría ahondar más en las instrucciones y las diferentes labores que tenían los jueces pobladores, se dejará hasta este punto, dado que en el siguiente apartado se incluirán otras labores de aquellos, pero ya vinculadas a la conflictividad que sus funciones generaban.

22 José María del Toro, "Relativa a la aprobación oficial de la fundación de San Carlos del Priego" (8 de noviembre de 1789) AHA, Colonia, RO, t. 4, ff. 2r, 2v.

23 José María del Toro, "Relativa a la aprobación oficial de la fundación de San Carlos del Priego" (8 de noviembre de 1789) AHA, Colonia, RO, t. 4, f. 7r, 7v, 8r, 8v. 


\section{Vida criminal en las colonias agrícola.}

Hasta ahora se ha dicho que las colonias agrícolas fueron establecidas formalmente en el último decenio del siglo XVIII, también se ha mencionado que estas no surgieron ipso facto, sino que fueron el resultado de un proceso histórico que primero, buscaba solucionar los problemas de abastecimiento de las jurisdicciones y segundo, agrupar a los pobladores que se hallaban dispersos a lo largo de la región con el fin de corregir sus comportamientos y entraran a participar en los ideales ilustrados que trajeron consigo las Reformas Borbónicas, de trabajar la tierra para hacerla productiva. Tomando como contexto lo anterior, es indudable que un lugar que agrupará a desposeídos, vagantes y a algunas personas prominentes de la sociedad, fuera el caldo de cultivo para que se presentaran conflictos, crimines, desmanes y demás desordenes. El presente capítulo pretende mostrar esas conflictividades generadas entre los habitantes de las colonias agrícolas, esto por medio de una fuente riquísima para detallar los conflictos: los juicios criminales.

La colonia de San Fernando de Borbón, fundada a finales del año 1788 con colonos de Itagüí, Envigado y Medellín, fue la protagonista de una serie de pleitos judiciales entre el juez poblador y otros vecinos que lo denunciaron en más de una ocasión. Para comprender dichas denuncias, se hace necesario aludir a uno de los implicados en el juicio, don Miguel Pérez de la Calle. Este fue un vecino reconocido de la villa de Medellín, quien el 25 de julio de 1788 se dirigió al visitador arguyendo que el lugar era propicio para establecer legalmente una colonia agrícola. ${ }^{24}$ Unos meses más tarde en diciembre del mismo año, fue nombrado juez poblador del sitio de Amagá. Al parecer, la familia Calle poseía ya grandes extensiones de tierra en el sitio, pues su hermano, don Ignacio Pérez de la Calle, (...) ofrece graciosamente el plan para iglesia plana, cárcel y ocho cuadras en cuadro de marco para poblarse los vecinos. ${ }^{25}$

En 1790, al mencionado Miguel Pérez de la Calle, se le imputo un juicio criminal por contrabando de aguardiente. La acusación ${ }^{26}$ la presento don Ramón Díaz,

$24 \quad$ Robledo, Bosquejo biográfico, 198.

25 "Documentos sobre tramite de fundación de San Fernando de Borbón, hoy Amagá", (Medellín 16 de abril de 1790) AHA, Colonia, FM, t. 41, hoja 33, f. 3v.

26 Es importante hacer una salvedad sobre lo que significaba ser acusador y denunciador para el siglo XVIII según la legislación española. Para ello recurriré a la historiadora Beatriz Patiño, quien da luces sobre lo anterior al decir que: "el acusador era quien denunciaba el delito al juez para tomar venganza (...) el denunciador por su parte, solo manifestaba al juez el delito cometido y su autor si lo sabía para que este procediera a practicar lo que le correspondía" - también anota que - "La posibilidad de ser acusador dependía de si el delito era público o privado. "El derecho español consideraba como público todo delito hecho en ofensa de Dios, en contra del príncipe o del Estado (...) esta clase de delitos le competía a todo el pueblo. Delito privado era el que ofendía y dañaba directamente a un particular. Beatriz Patiño Millán, Criminalidad, ley penal y estructura social en la Provincia de Antioquia. 1750-1820 (Medellín: IDEA, 1994) 62-63. De esta manera, en el caso arriba expuesto don Ramón Díaz era un acusador, puesto que pretendía vengarse y era un delito público, en el sentido que este iba en contra de las arcas del Estado. 
quien le manifestó al juez que Miguel Pérez, celebró un fandango en su casa el que al parecer, estaban bebiendo aguardiente el cual no era lícito; esto según los testigos entrevistados por el juez pedáneo. Por este hecho, el juez poblador fue puesto bajo prisión y en su defensa dijo,

(...) en mí no ha habido la menor culpa ni admisión, y que esta acusación, que se ha inventado por don Ramón Díaz ha sido llevado la siega pasión y enemiga declarada que tiene contra mí por hallarse de reo en la causa que le seguí, y que evidentemente se conoce haberla hecho solo por este fundamento particular (...) En cuya virtud, suplico reverentemente a vuestra señoría que teniendo como tengo pedido de antemano el que se me conceda soltura de esta prisión. ${ }^{27}$

Efectivamente Miguel de la calle fue dejado en libertad el cuatro de junio de 1791 bajo lo que Patiño define como la fianza de "pagar lo juzgado", que estaba limitada a las penas que se podrían pagar con dinero siempre y cuando existiese un fiador que se hiciera responsable de pagar en que caso de que el reo no lo hiciese. ${ }^{28}$

Pero este no fue la única causa que se le siguió a don Miguel de la Calle. En 1791, se levantó otro proceso, en el cual, también estaba implicado su hermano, el mismo que donó las primeras tierras para levantar la nueva población del sitio de Amagá, don Ignacio Calle. Esta vez, la acusación fue realizada por los vecinos y por el mismo litigante anterior Ramón Díaz, quienes alegaban falta de cumplimento en sus labores, como por ejemplo la falta de construcción de la iglesia. ${ }^{29}$ Igual que en el juicio anterior de la Calle, en su defensa, retoma casi los mismos argumentos y dice:

(...) haré demostrable en este la voluntariedad y falsedad con que por estos se ha procedido, sin que hayan justificado, o probado cosa alguna correspondiente a la tal demanda, o queja, que instauraron contra mí (...)en esos autos de que tuve presos a tal y cual de aquellos habitadores, y que fue por inobediencia a los preceptos, que como juez les imponía como se deduce de las mismas pruebas, que el citado don Ramón produjo desde el folio 59 hasta el 60; y sobre cual pido la atención de Vuestra Señoría para que se conozca la temeridad con que estos pobladores y su Capitán han procedido contra mí. ${ }^{30}$

Se observa pues, cómo solo unos pocos años de haberse fundado San Fernando de Borbón ya comenzaban a existir conflictos, que, aunque las fuentes consultadas

27 "Contra Miguel Calle por contrabando de aguardiente", (Medellín 15 de abril de 1789) AHA, Colonia, Juicios criminales, caja B-96, leg 1790-1800, documento No 5, ff. 20r.

28 Patiño Millán, Criminalidad, ley penal, 85.

29 "Contra: don Miguel Calle, y don Ignacio calle, jueces pobladores de Amagá por falta de cumplimiento en sus deberes" (Medellín 1791) AHA, Colonia, JC, caja B-64, Leg 1790-1800, Documento No 2, ff. 158, 159.

30 "Contra: don Miguel Calle, y don Ignacio calle, jueces pobladores de Amagá por falta de cumplimiento en sus deberes" (Medellín 1791) AHA, Colonia, JC, caja B-64, Leg 1790-1800, documento No 2, ff. 1v. 
no lo especifiquen, se puede inferir que el pleito llevado a cabo entre don Miguel de la Calle y don Ramón Díaz, escondía otros interés, tales como la apropiación o el acaparamiento de terrenos o la conservación de una especie de estatus que los hiciera sobresalir ante los colonos de los cuales Ramón Díaz se valió para formular su denuncia. De cualquier manera, es factible que se presentaran casos, como el anterior, dentro de las colonias agrícolas, pues no solo fueron tierras concedidas a la población más pobre, sino que también algunas personas, como la familia Calle, buscaban seguir acrecentando sus propiedades, valiéndose de sus posiciones como funcionarios, por lo menos esto es lo que se puede deducir.

Obviamente, dentro las colonias agrícolas, también se presentaron otros conflictos o crímenes que se podrían catalogar, del ámbito cotidiano, tales como el concubinato, las injurias, agresiones y riñas entre los mismos colonos u otros delitos comunes. A continuación, se enunciarán algunos casos que reflejan la conflictividad en los nuevos asentamientos.

Aunque no se enunciaran todos los casos criminales encontrados que sucedieron en las colonias agrícolas por cuestiones de espacio, se debe decir que la mayoría de ellos tuvieron lugar en la colonia de San Luis de Góngora - Yarumal- Haría falta un estudio más detallado para entender el porqué, pues en esta investigación no se abordará. Ahora bien, fue precisamente en aquella población donde el 14 de julio de 1791, don Vicente Jaramillo denunció a Rudesindo Jaramillo porque este había herido a su mujer, la cual se llamaba Manuela López. Inmediatamente, según lo relata el juez pedáneo del sitio de Yarumal, “(...) mando que el citado Jaramillo se mantenga en la prisión y se le doble la guardia en tanto que se reconocen las heridas". ${ }^{31}$

El juicio prosiguió, y el juez mandó llamar a los testigos que presenciaron el acto para esclarecer las causas que motivaron a Rudesindo Jaramillo para golpear su mujer; uno de ellos, nombrado José Salvador que estuvo presente el día del hecho, le dijo al juez que los esposos estaban discutiendo, porque Manuela López no retiraba unos "trastes" que, según Jaramillo estaban estorbando; unos minutos más tarde el marido tomo un machete e hirió a la mujer en la cabeza y las manos; el mismo testigo también dice que ante este acto ella se defendió lanzándole una hacha. ${ }^{32}$

Según Beatriz Patiño, el mundo doméstico de finales del periodo colonial fue muy violento y fueron constantes los ataques entre los mismos miembros de la familia como lo especifica el caso anterior. La misma autora explica, además, que dichos casos se presentaban porque existía la creencia de que los padres podían castigar fuertemente a sus hijos o esposas. ${ }^{33} \mathrm{Al}$ parecer, la anterior creencia estaba muy difun-

31 "contra Rudesindo Jaramillo por haber herido a su mujer Manuela López" (Yarumal, 14 de julio de 1791) AHA, Colonia, JC, caja B-76, Leg 1790-1796, Documento No. 4, ff. 1 r.

32 "contra Rudesindo Jaramillo por haber herido a su mujer Manuela López" (Yarumal, 15 de julio de 1791) $A H A$, Colonia, $J C$, caja B-76, legajo 1790-1796, Documento No. 4, ff. 2r.

33 Patiño, Criminalidad, 284. 
dida, porque en la sentencia del juez sobre el caso entre los dos esposos, legitima el comportamiento de Jaramillo, aunque esta se haya defendido:

Deseando este juzgado la buena armonía que debe haber entre casados y que por ningún motivo de desavenencia estén estos separados, se les notificará a Rudesindo Jaramillo, y a Marcela López, vivan en paz sin provocarse uno, a otro, ni menos ponerse la mano violenta, como indebidamente ha ejecutado dicho Jaramillo (...) cuyo hecho, y el de haber aquella acometidole con el hacha hasta tirarle un golpe, faltándole al respeto del marido. ${ }^{34}$

El siguiente juicio criminal va encaminado a mostrar uno de los delitos más denunciados durante el siglo XVIII: las injurias, que tenían el fin de desprestigiar a otras personas por su condición racial, poner en duda la honradez de un individuo, acusar de ladrón y concubinato, etcétera. Las injurias verbales, como asegura Beatriz Patiño, siempre se daban entre personas que se conocían y que eran vecinos de un mismo lugar, con el fin de tomar venganza. ${ }^{35}$

Así sucedió en el Sitio de San Luis de Góngora, donde tuvo lugar una querella entre el colono don Cosme Zapata y el juez poblador don Vicenta Peña; este último acusó a Zapata, según él, porque a pesar de estar casado con su mujer no estaba viviendo con ella. En su defensa Cosme dice:

(...) que aquel juez D. Vicente Peña, olvidado de que el mismo, como consta de autos, ha publicado mi irreprehensible conducta, y apartado de lo que previenen las leyes, se excedió a seguirme causa criminal procurando manchar mi honor, con la imputación del horroroso delito de adulterio. Además anota que: (...) Como el juez, y su director son mis desafectos, y los testigos que buscó mis capitales enemigos, llenos de vicios y defectos; consideré seria en todos grande el empeño a destruir mi buena reputación, fama e intereses. ${ }^{36}$

La razón, por la que Cosme resalta de manera continua que con la acusación se está perjudicando su buen nombre y su honor, puede relacionarse, según Patiño, con que para la época, los hombres eran los encargados de mantener el honor de la familia y para muchos, conservar su decoro era seguir conservando su estatus social. ${ }^{37}$ Por lo tanto, para tratar de salvar esto, Cosme dice tener legítima causa para vivir separado se mujer; arguye que no vive con ella porque esta le fue infiel, y que según las disposiciones del derecho divino y humano no debe ser obligado a vivir bajo el mismo techo. ${ }^{38}$

34 "contra Rudesindo Jaramillo por haber herido a su mujer Manuela López", (Yarumal, 29 de agosto de 1791) AHA, Colonia, $J C$, caja B-76, Leg 1790-1796, Documento No 4, ff. 8r.

Patiño Millán, Criminalidad, 223.

35 Patiño Millán, Criminalidad, 223.

36 "Contra don Cosme Zapata por no quererse juntar con su esposa" (Yarumal, 30 de mayo de 1804) AHA, Colonia, $J C$, caja B-98, Leg 1800-1810, Documento No 2, ff. 13r, 13v.

Patiño Millán, Criminalidad, 200.

37 Patiño Millán, Criminalidad, 200.

38 "Contra don Cosme Zapata por no quererse juntar con su esposa" (1804) AHA, Colonia, JC, caja B-98, Leg 1800- 
Aunque se podrían seguir mostrando más ejemplos de los demás juicios criminales existentes en las colonias agrícolas, se dejará hasta este punto dado que la mayoría de ellos están vinculados a los conflictos arriba expresados. También se debe advertir que, a pesar de que el conjunto de las personas que habitaban las colonias eran pobres, no se encontró ningún juicio criminal que hablará o por lo menos mencionará a dicha población. ${ }^{39}$

\title{
Conclusiones
}

Las colonias agrícolas trabajadas a lo largo del artículo, fueron útiles, en teoría, para dar solución a los problemas de abastecimiento de los grandes centros poblados de la provincia. A la vez, también fueron el marco perfecto para agrupar a la población dispersa que se encontraba aglutinada alrededor de las ciudades bajo la condición de vagos, llevar a este tipo de población a esos centros de colonización y poblamiento, bajo la promesa de unos cuantos terrenos en los cuales debían trabajar para ganar su sustento, fue algo común a finales del siglo XVIII. Ahora, según Mauricio Arango, el proceso de adjudicación de tierras para los individuos o familias pobres, en realidad, se vio frustrado por los intereses de grandes propietarios. Esto quiere decir que realmente las colonias agrícolas no consiguieron, a cabalidad, el fin que tanto persiguió Mon y Velarde. Los conflictos mencionados dentro de los poblados, también van enmarcados en señalar la disparidad que existió al interior, puesto que al igual que sucedió en Amagá con la familia Calle, donde estos aprovechando su posición fueron en busca de más tierras, es probable que también que en las demás colonias haya pasado lo mismo.

Por último, vale la pena señalar que, además de los conflictos por la tierra entre unos y otros, siempre en toda sociedad, sea recién establecida o lleve constituida un tiempo, van a existir desencuentros generados por la misma interacción cotidiana, que conlleva a que se agudicen las relaciones sociales o, en su defecto, a que se establezcan lazos, todo dependerá del contexto.

\section{Bibliografia}

\section{Fuentes primarias}

\section{A. Fuentes manuscritas}

\author{
Archivo histórico de Antioquia, Medellín (AHA). \\ Sección Colonia
}

1810, Documento No 2, ff. 36r.

39 A excepción de un juicio criminal ocurrido en el sitio de Sacaojal, donde una pareja que vivía amancebada y malentretenida, fue sentenciada al destierro al sitio de San Luis de Góngora. 
Fundación de municipios (FM)

Juicios criminales (JC)

Reales Ordenes (RO)

\section{B. Fuentes impresas}

Robledo, Emilio. "Sucinta Relación" Bosquejo biográfico del señor oidor Juan Antonio Mon y Velarde Visitador de Antioquia, 1785-1788. Bogotá: Publicaciones del Banco de la República, 1954.

\section{Fuentes secundarias}

Arango Puerta, Mauricio. "Poblamiento agrícola en la provincia de Antioquia, 1754-1812" Monografía de pregrado, Universidad Nacional de Colombia-sede Medellín, 2010.

Campuzano Cuartas, Rodrigo. "Fundaciones de Yarumal, Sonsón, San Carlos y Amagá" Monografía de pregrado, Universidad de Antioquia, 1986.

Colmenares, Germán. "La formación de la economía colonial (1500-1740)”. En Historia económica de Colombia. José Antonio Ocampo, Coord. Bogotá: 1987.

Jaramillo, Roberto Luis. "Colonizaciones en Antioquia". En Geografía de Antioquia, editado por Michel Hermelin. Medellín: Fondo Editorial Universidad Eafit, 2007.

Jurado Jurado, Juan Carlos. Vagos, pobres y mendigos. Contribución a la historia social colombiana, 1750-1850. Medellín: La Carreta Editores, 2004.

Montoya, Juan David. "Antioquia: población y territorio en las postrimerías del periodo colonial.” Historia y Sociedad 14 (2008).

Patiño Millan, Beatriz Amalia. Riqueza, pobreza y diferenciación social en la Provincia de Antioquia del siglo XVIII. "Informe final de la investigación" "Clases sociales y razas en Antioquia en la Antioquia del siglo XVIII" Medellín: Facultad de Ciencias Sociales y Humanas, Universidad de Antioquia, 1985. 
- Criminalidad, ley penal y estructura social en la Provincia de Antioquia. 1750-1820. Medellín: IDEA, 1994.

Robledo, Emilio. Sucinta Relación. Bosquejo biográfico del señor oidor Juan Antonio Mon y Velarde Visitador de Antioquia, 1785-1788. Bogotá: Publicaciones del Banco de la República, 1954.

Valenzuela Márquez, Jaime. Fiesta, rito y política. Del Chile borbónico al Republicano. Santiago: Dirección de Bibliotecas, Archivos y Museos, 2014. 